\title{
Emergency Department MR Imaging Scanner: Supportive Data
}

W e read with personal interest the article in the May 2017 American Journal of Neuroradiology by M. Buller and J.P. Karis entitled "Introduction of a Dedicated Emergency Department MR Imaging Scanner at the Barrow Neurological Institute.” The authors described the challenges of placing an MR scanner in the emergency department (ED) setting in 2015 and referred to the impact on workflow. They also speculated on the impact this may have on patient care and decision-making. Our analyses on these issues regarding the installation of our ED MR scanner in 2012 have recently been published or are in press. The issues of length of stay (LOS) in the ED versus hospital LOS are areas of appropriate investigation, which we have explored in the settings of stroke $^{1,2}$ and multiple sclerosis. ${ }^{3,4} \mathrm{We}$ also have analyzed the impact of MR imaging on the decisions to admit patients, which may decrease unnecessary admissions, another downstream impact. ${ }^{1-4}$

One important issue that we learned when we installed our ED CT scanner in 1999 is to have an agreed upon list of indications for emergent versus nonemergent but appropriate imaging requests. ${ }^{5}$ For the MR scanner installation, we met with the ED, neurosurgery, neurology, trauma surgery, and otorhinolaryngology departments and came up with a consensus list of ED MR imaging indications. This has led to satisfaction by all parties and less "drift" to inappropriate imaging.

http://dx.doi.org/10.3174/ajnr.A5315
Disclosures: David Yousem—UNRELATED: Expert Testimony: consultant for Expert Witness testimony, Comments: self-employed; Payment for Lectures (including service on Speakers Bureaus): ACR Education Center*; Royalties: Elsevier, Comments: for 5 books. *Money paid to the institution.

\section{REFERENCES}

1. Redd V, Levin S, Toerper M, et al. Effects of fully accessible magnetic resonance imaging in the emergency department. Acad Emerg Med 2015;22:741-49 CrossRef Medline

2. Honig SE, Honig EL, Mirbagheri S, et al. The impact of installing an MR scanner in the emergency department for patients presenting with acute stroke-like symptoms. Clin Imaging 2017;45:65-70 CrossRef Medline

3. Pakpoor J, Saylor D, Izbudak I, et al. Follow-up of emergency department MRI scans suggesting new diagnosis of CNS demyelination. AJR Am J Roentgenol 2017;209:171-75 CrossRef Medline

4. Pakpoor J, Saylor D, Izbudak I, et al. Emergency department MRI scanning of patients with multiple sclerosis: worthwhile or wasteful? AJNR Am J Neuroradiol 2017;38:12-17 CrossRef Medline

5. Oguz KK, Yousem DM, Deluca T, et al. Effect of emergency department $\mathrm{CT}$ on neuroimaging case volume and positive scan rates. Acad Radiol 2002;9:1018-24 CrossRef Medline 